\title{
Epoché no método de Design
}

\author{
Epoché in the Design method
}

\author{
por Camila de Cássia das Dores Ogava, Erik Silva dos Santos, \\ Alberto Ribeiro Palmieri, Richard Perassi Luiz de Sousa, \\ Eugenio Andrés Díaz Merino e Luiz Fernando Gonçalves de Figueiredo
}

\begin{abstract}
RESUMO
funcionalista, é influenciada pelo pragmatismo e busca na metodologia instrumentos para ampliar a assertividade da concepção de projetos, onde a satisfação do usuário é o principal critério de validação das soluções de design. Debate-se então a necessidade do profissional de design lidar com fatores estéticos segundo o juízo de valor do usuário, de modo que sua própria opinião tenha menor peso nas decisões ligadas à estética. Utilizando-se de pesquisa teórica, buscou-se compreender a suspensão do juízo (epoché) proposta pelos céticos antigos, visando a possibilidade de contribuição na aplicação desta ao método de design como um instrumento, respeitando os fins pragmáticos da profissão.
\end{abstract}

Palavras-chave suspensão do juízo (epoché); design; estética; método

ABSTRACT

The design activity, as a functionalist industrial occupation is influenced by pragmatism and seeks tools on methodology to expand the assertiveness of design projects, where user satisfaction is the main criterion for validation of design solutions. Thus, we discuss the need for the designer to deal with aesthetic factors according to the value judgment of the user, applying less value in your opinion, in decisions related to aesthetics. Through theoretical research, we sought to understand the suspension of judgment proposed by the ancient skeptics, to contribute in this application, in design method as a tool and according to the pragmatic purposes of the profession.

Keywords suspension of judgment (epoche); design; method 


\section{Introdução}

Segundo Papanek: "Todos os homens são designers. Tudo o que fazemos, quase 0 tempo todo, é design, pois o design é básico para todas as atividades humanas" (PAPANEK, 1991 apud MOZOTA et al., 2011, p. 15). Tal afirmação é valida se aceito que a atividade de design está implícita e dispersa em outras atividades, pois estas também precisam ser concebidas em projetações e designações, como no caso do artesão que durante 0 processo de produção vai projetando o artefato, existindo assim a atividade de design, ainda que não em um momento explícito e dedicado.

Segundo Martins e Merino (2011, p. 42) o design existe desde os primórdios da evolução humana no desenvolvimento de artefatos e símbolos, ainda que rudimentares. De modo que, como processo profissional e área de formação acadêmica, o design surge em meio à revolução industrial a partir do século XVIII, proveniente da fragmentação de todo o processo produtivo em busca do "melhor fazer", através da dedicação exclusiva a etapas determinadas, que antes cabia a um único profissional. Assim, o design que estava disperso e implícito no artesanato, passou a ser uma atividade explícita, dedicada e condensada, responsável pela concepção de produtos industriais em busca do "melhor projetar".

Esta postura profissional em meio ao contexto industrial permite a observação, relevante neste artigo, de que a industrialização se fundamentou no positivismo e, posteriormente, no pragmatismo, de modo que o design também compartilha destas bases, onde é valorizado o sucesso da aplicação da ideia, a utilização do resultado (OLHATS et al., 2011). Neste contexto industrial o aspecto técnico-científico do design passa a construir métodos em busca da assertividade e da eficiência dos produtos, firmando um caráter funcionalista.

Sendo que, como critério para validar a funcionalidade do produto concebido, instaurou-se a satisfação na relação usuário/produto, pois o design, enquanto atividade tem origem no termo latim "designare", que é traduzido como "designar", sendo compreendido como "dar significado e/ou símbolo", fazendo pressupor a interação do produto concebido com um usuário, pois só assim pode existir "significância".

No entanto, quando esta atividade passa a ser uma profissão dedicada, há separação do "indivíduo designer" e do "usuário", uma vez que não é mais o artesão quem projeta para seus semelhantes próximos ou para si mesmo, mas sim uma indústria que produz em massa para um grande número de usuários, sendo o designer responsabilizado pela acessibilidade, funcionalidade e satisfação para com os produtos concebidos criteriosamente segundo a percepção do usuário.

Com um caráter funcionalista e centrado no usuário, iniciou-se o desenvolvimento de estudos e métodos que quantifiquem esta relação usuário/produto e forneça parâmetros de assertividade aos projetos, como é o caso da ergonomia e de análise de custos, existindo, no entanto, dificuldades quanto a fatores qualitativos como, por exemplo, os atributos estéticos. 
Como base nestes aspectos, levanta-se neste artigo a necessidade do profissional de design em trabalhar, durante o processo metódico de concepção do projeto, fatores estéticos segundo os juízos de valores dos usuários, desvinculando o seu juízo quanto aos valores atribuídos e abordados. Posteriormente relaciona-se tal necessidade com o pensamento cético clássico que propõe a "suspensão do juízo".

Faz-se a ressalva de que a proposta deste artigo não é se aprofundar no tema do pragmatismo em torno do design, mas tê-lo como evidente e constante, logo a contribuição cética que se busca tem por pressuposto um fim pragmático, fazendo necessário abordar aqui o instrumentalismo, que é uma vertente do ceticismo moderno vinculado ao pragmatismo.

Para tanto, confronta-se esta problemática de design com o pensamento cético em um debate dedutivo, utilizando, para tanto, pesquisa teórica, compreendendo os assuntos abordados, através de periódicos, artigos científicos e livros de diversos autores (GIL, 1991).

\section{Design e o Método}

"Pensar o Design sem a preocupação com a metodologia adequada a sua execução, na maioria das vezes, leva o projeto ao fracasso" (GOMEZ, PEREIRA e SCHLEMPER, 2010, p. 01). Tendo em vista a importância da metodologia para o design, buscaram-se as origens desta no discurso do método científico a fim de entender suas contribuições.

A importância do método aplicado à pesquisa científica está em atenuar a influência da opinião própria do responsável pelo processo, a fim de maximizar a imparcialidade na experiência desenvolvida. Isso ocorre uma vez que o ser humano, devido ao conhecimento empírico, faz uso das informações com base nas suas experiências, crenças culturais e pessoais. A parcialidade é fator de empecilho, em qualquer situação, pois os resultados obtidos no meio científico servem como base para novas pesquisas e limitam assim, a assertividade.

A metodologia é o estudo dos métodos ligados à solução de problemas. " 0 conceito método deriva etimologicamente do greco-latino e significa caminho para alguma coisa, seguir ou andar ao longo de um caminho" (MERINO, GONTIJO e MERINO, 2011, p. 70).

Originariamente devida a Descartes, a metodologia propõe chegar à verdade através da dúvida sistemática e da decomposição do problema em pequenas partes, características estas que definiram a base da pesquisa científica (LANA, 2011, p. 55). No Discurso do Método, obra original datada de 1637, Descartes apresenta 0 método descrito através de quatro preceitos e que apontam claramente a eficácia do seu uso, para obter a verdade:

0 primeiro era 0 de jamais acolher alguma coisa como verdadeira que eu não conhecesse evidentemente como tal; isto é, de evitar cuidadosamente a precipitação e a 
prevenção, e de nada incluir em meus juízos que não se apresentasse tão clara e distintamente a meu espírito, que eu não tivesse nenhuma ocasião de pô-lo em dúvida.

0 segundo, o de dividir cada uma das dificuldades que eu examinasse em tantas parcelas quantas possiveis e quantas necessárias fossem para melhor resolvê-las.

0 terceiro, o de conduzir por ordem meus pensamentos, começando pelos objetos mais simples e mais fáceis de conhecer, para subir, pouco a pouco, como por degraus, até o conhecimento dos mais compostos, e supondo mesmo uma ordem entre os que não se precedem naturalmente uns aos outros. E o último, o de fazer em toda parte enumerações tão completas e revisões tão gerais, que eu tivesse a certeza de nada omitir (DESCARTES, 1973, $2^{\circ}$ parte).

Segundo Moraes đt Mont'Alvão (2009), o pesquisador procura conhecer e interpretar a realidade, interessa-se em descobrir e observar fenômenos e procura descrevê-los, classificá-los e interpretá-los. Sendo assim, a função do método é proporcionar um padrão e um direcionamento objetivo no desenvolvimento de estudos, produzindo resultados eficazes.

As características descritas no método foram sendo rearranjadas a fim de cumprir seu papel nas diversas áreas do conhecimento. Para esse estudo deverá ficar claro a função do método aplicado ao design. A atividade profissional de design é metodológica e caracteriza-se por uma série de procedimentos reconhecidos pela academia científica, "sem o método, o que resulta não é design, mas o acaso, que não permite valoração quantitativa e ou qualitativa, repetição ou aprimoramento". (LANA, 2011, p. 60). Para Moraes (2011), as metodologias, cada vez mais, se sistematizam para levar em consideração fatores psicológicos, semânticos, da interface e até mesmo de sentimentos, visando desenvolver produtos que satisfaçam às necessidades do homem moderno, tornando-se mais eficazes.

\section{Design e a estética}

Quanto à compreensão do design como profissão, no cenário brasileiro, pode-se verificar no Projeto de Lei nć. 3.515 de 1989, que visava à regulamentação desta atividade, citado por Niemeyer (2007, p. 23), onde se atribui ao design as "atividades especializadas de caráter técnico-científico, criativo e artístico, visando à concepção e o desenvolvimento de projetos", onde projeto é o "meio em que o profissional, equacionando de forma sistêmica dados de natureza ergonômica, tecnológica, econômica, social, cultural e estética, responde concreta e racionalmente às necessidades humanas".

Observa-se, então que os atributos estéticos dos produtos estão entre as responsabilidades do design, variando o grau de importância segundo os objetivos e 0 
contexto do projeto, considerando que a relação entre usuário e objeto também se dá em um nível emocional.

\begin{abstract}
Observa-se, na inquietude do homem contemporâneo, um forte apelo à beleza, ao que é belo, para complementar sua existência, pois as sensações espirituais, deduzidas da beleza, transmitem ao ser humano um elevado sentimento de felicidade, serenidade e prosperidade (LISBOA e BISOGNIN, 2003, p. 07).
\end{abstract}

Segundo Japiassú e Marcondes (2001) a palavra estética deriva do grego "aisthetikós", de "aisthaianesth" que tem o sentido de "perceber", "sentir", referindo-se a empina do gosto subjetivo, àquilo que agrada aos sentidos. Esta afirmação esteve por muito tempo, ligada às artes consideradas o símbolo da estética. Bomfim (1998) corrobora com esta afirmação, mas a aproxima do campo do design quando destaca que "sabe-se que os valores estéticos não são encontrados apenas no campo da arte (...), mas também do Design".

Para Willian James, segundo Caviquiolo et al. (2006) "cada objeto que excita um instinto excita também uma emoção, ou seja, é impossível manter-se indiferente diante de qualquer objeto, independente se esta emoção gerada é positiva ou negativa".

A experiência que ocorre no momento em que um usuário interage com o produto é fundamental para o sucesso ou não deste. Nesta experiência atuam três tipos de universo: do usuário, do produto e do contexto de uso, e esses três universos interagindo irão determinar se ela será boa ou ruim (ARHIPPAINEN, 2003). Pelas observações visuais que se fazem do mundo, na percepção das diferentes formas dos objetos que compõem o espaço que atendem às necessidades do homem, torna-se natural a preocupação com a aparência deles, pois se trata do seu conforto, bem-estar, da satisfação e, consequentemente, está sujeito as emoções, o que implica numa relação de uso (LISBOA e BISOGNIN, 2003).

Lobach (2001, p. 59) define que "a função estética dos produtos é um aspecto psicológico da percepção sensorial durante o seu uso".

Para Munari (1993 apud MOURA, 2005) a arte e a estética são importantes e devem estar presentes nos objetos e produtos de design. Não é a arte destinada à contemplação pura, a fruição estética e sim a arte para o cotidiano, para o uso nos atos da vida, onde produtos são desenvolvidos com finalidades que geram especificidades e prazer na utilização, povoando o universo material distante e além do supérfluo.

Portanto há de se esclarecer a íntima ligação entre o desenvolvimento no projeto de produtos, a estética e o usuário. Para este estudo, esta relação se estabelece quando o profissional se abstém do seu próprio juízo de valor em prol do contentamento, ou seja, da satisfação do usuário final. 0 designer "bem sucedido é aquele que consegue pensar com a mente do consumidor: ele consegue interpretar as necessidades, sonhos, desejos, valores e expectativas do consumidor" (BAXTER, 2003, p. 33), a partir da interpretação será possível ao profissional do design se utilizar 
dos métodos existentes para alcançar a interação entre as fases da projetação e alcançar resultados que realmente atendam aos anseios do consumidor.

\section{Pensamento cético}

0 filósofo da Grécia antiga, Pirro de Élis, é apontado como o fundador do pensamento cético, entre os séculos IV e III a. C.. O ceticismo é a concepção segundo a qual o conhecimento do real é tido como impossível à razão humana, propondo, portanto, que o homem deva renunciar à certeza, suspender seu juízo sobre as coisas e submeter toda afirmação a uma dúvida constante (VERDAN, 1998; JAPIASSÚ e MARCONDES, 2001).

Segundo a passagem de Diógenes Laércio, citada por Verdan (1998, p.20):

(Pirro) sustentava que não existe nem o belo nem o feio, nem o justo nem o injusto; que nada existe realmente, mas que em todas as coisas os homens se governam segundo o costume e a lei. Pois uma coisa não é mais isto do que aquilo.

Nesta linha de pensamento é proposto que se abstenha de formular ou adotar dogmas, estabelecendo-se em uma distância igual entre afirmações e negações, pois não se pode afirmar a realidade das coisas, uma vez que o homem é incapaz de perceber sua real natureza estando limitado por pré-conceitos, pela subjetividade e pela limitação dos sentidos humanos, portanto, o ceticismo se firma na prática da dúvida, e não na busca por afirmações ou verdades absolutas.

Entre as várias vertentes do ceticismo clássico destaca-se aqui o empirismo no qual se filiou Sexto Empírico, filósofo que viveu entre os séculos III e II a. C., e que sistematizou o pensamento de Pirro (pirronismo) em textos e livros permitindo o ceticismo moderno e os estudos até hoje realizados sobre este tema (JAPIASSÚ e MARCONDES, 2001). Para o empirismo, todo conhecimento humano deriva, direta ou indiretamente da experiência sensível externa ou interna, de modo que se aceita a existência dos fenômenos/objetos, mas que não se pode ter certeza de sua realidade devido à deficiência da percepção humana, e das influências exteriores, tornando a situação duvidosa e relativa, não permitindo a concepção de opiniões ou razões.

Dutra (2005, p. 26) cita o exemplo apresentado pelos céticos antigos: "Se vemos uma torre de longe, ela pode nos parecer redonda; e quando nos aproximamos, ela nos parece quadrada; se de novo recuamos, ela volta a nos parecer redonda". Este exemplo ilustra tanto a relatividade da percepção, quanto a inconstância conflituosa entre as opiniões que podem ser geradas sobre um mesmo objeto observado.

Mediante a inquietude e a impossibilidade de se ter a verdade de algo, bem como a grande variação de opiniões e valores aos mais diversos casos é que se propõe como solução a "suspensão do juízo", do termo grego "epoché". Verdan (1998, p. 38) corrobora mencionado que: 
(...) Não há um argumento que não possa ser derrubado por um argumento contrário, igualmente convincente. Esta (...) igual força da razão em disputa, é a causa direta da suspensão do juízo. Incapazes de poder dar seu assentimento a um argumento em detrimento de outro, a uma tese antes que a opinião contrária, os céticos renunciaram se pronunciar.

Mora (1978, p. 86), cita Sexto Empírico afirmando que epoché "é estado de repouso mental pelo qual nem afirmamos, nem negamos", um estado que conduz à imperturbabilidade (ataraxia). A crítica que é encontrada à epoché, é quanto à tendência de que esta provoque uma inação, uma incapacidade de agir mediante a ausência de uma opinião, como é colocado por Marcondes (2007). Em resposta a esta questão, Verdan (1998, p. 52) cita a colocação de Sexto Empírico, onde fica claro que os céticos não deixavam de realizar tarefas cotidianas, apenas não afirmavam sobre estas:

"Não aplicamos, sem distinção, nossas expressões céticas a todos as coisas do mundo. Somente a empregamos para as coisas inacessiveis aos sentidos e relativas ao dogma. Admitimos o fenômeno tal qual ele nos parece, não emitimos opiniões positivas sobre a natureza das coisas exteriores".

Ainda quanto ao ceticismo, no entanto agora em um contexto moderno, destaca-se aqui, ainda que brevemente, sua vertente instrumentalista, que provém de um realce do ceticismo a partir do pragmatismo, que, como já visto, interessa neste artigo, pois há uma relação com os princípios do design industrial. 0 Instrumentalista basicamente advém da impossibilidade dos pragmáticos de afirmarem uma verdade, mas que precisavam dar continuidade à construção do conhecimento. Assim, o instrumentalismo não se preocupa com a validação das teorias como verdadeira ou falsas, mas sim de validar teorias segundo a utilidade destas para estudos posteriores (DUTRA, 2005).

\section{Aplicação do conceito de epoché ao método do design}

Como visto no conteúdo até aqui levantado, o design como profissão, busca nos métodos a assertividade, utilizando-se de etapas tais como levantamento da problemática, pesquisa e desenvolvimento de alternativas para chegar a uma proposta tida como solução. Portanto, em vários momentos, o profissional de design é um "decisor/moderador" quanto à quais critérios da problemática serão abordados, e as escolhas dentre as alternativas geradas. Sendo que, como visto, os critérios devem ser centrados no usuário. Neste âmbito algumas decisões podem ser respaldadas em estudos técnicos e científicos, o que, não necessariamente ocorre, principalmente com questões estéticas.

Como afirma as autoras Pombo e Tschimmel (2002, p. 4) segundo sua experiência, "cada designer interpreta um problema de design de modo diferente e subjetivo, 
de forma que cada solução de design é uma opção pessoal e específica de cada designer/grupo de designers". Observa-se então que há uma distância entre a teorização do ideal e as práticas aplicadas.

Sob uma perspectiva empirista, o designer não abandonará sua percepção de realidade, pois na etapa de criação este precisa manipular informações para gerar as alternativas, e para tanto só poderá manipular aquelas com as quais teve contato, logo usará seu conhecimento pessoal e empírico. Então neste artigo a epoché é apontada como uma opção útil ao método de design em etapas que requerem decisões quanto à estética e não necessariamente às etapas criativas.

Considerando que, se o designer faz as escolhas para o projeto segundo seu próprio juízo de valor, logo o produto concebido atenderá aos requisitos e terá os atributos estéticos segundo o que este julgou correto, enquanto o produto é direcionado a pessoas de juízos de valores possivelmente diferentes. Neste caso o usuário somente avaliará o produto quando esse já estiver sendo produzido em massa, e poderá não ter suas necessidades e/ou expectativas atendidas, vindo a ficar insatisfeito e recusando o produto, o que não é interessante ao usuário e nem a indústria que requer assertividade na concepção dos projetos.

Em contrapartida, pode haver também a insatisfação ou recusa do designer ao projetar algo no qual ele não acredita ter uma boa forma, cor, textura e etc., não atendendo seus a dogmas estéticos.

Neste caso, a epoché pode ser aplicada ao método do desenvolvimento de produtos nas etapas que requerem decisões, de forma que o profissional de design busque suspender seu juízo de valores, tentando não afirmar qual a necessidade ou a forma ideal e/ou errada segundo sua percepção, mas sim, compreendendo os juízos de valores dos usuários alvos como objetos de estudo de modo a tê-los como parâmetro para as decisões, aproximando o usuário do processo. Faz-se a observação de que a epoché é uma busca constante, que aplicada em um contexto puramente cético, pode levar a uma estagnação do processo de decisão, mas no caso do design deve-se respeitar suas bases pragmáticas, logo a epoché teria fins pragmáticos e, portanto, instrumentalistas, ou seja, uma suspensão de juízo parcial e instrumental que vise resultados mais eficientes.

\section{Considerações Finais}

Então, observou-se neste artigo que o design como profissão industrial busca no método um instrumento para assegurar a assertividade no desenvolvimento de projetos, tendo então o design um caráter pragmático por visar a aplicação do produto resultante.

E, sob pesquisa teórica e discurso lógico dedutivo, conclui-se que a epoché sugerida pelos céticos antigos, aplicada ao método do design como um instrumento de 
fins pragmáticos, é uma opção válida às etapas onde o profissional de design toma decisões estéticas, ligadas a sua percepção da problemática bem como da escolha das alternativas geradas. Nesse sentido, o exercício da epoché ajudaria a colocar o juízo de valor do usuário como centro da concepção de projeto, bem como auxiliaria o profissional de design a colocar-se em um estado de ataraxia, ou seja, de imperturbabilidade evitando o conflito entre suas opiniões e as do usuário.

Para estudos posteriores, sugere-se o aprofundamento desta proposta de aplicar a epoché ao método de design sob estudo exploratório, onde se possa verificar como tal prática ocorre e com qual frequência e/ou a proposição de experimento desta. 


\section{Referências}

> ARHIPPAINEN, L.. Capturing user experience for product design. IRIS26, The 26th Information Systems Research Seminar in Scandinavia, 2003.

> BAXTER, Mike. Projeto de produto - guia prático para o design de novos produtos. São Paulo: Ed. Edgard Blücher, 2003.

> BOMFIM, Amarante Gustavo. Idéias e formas na história do Design: uma investigação estética: Ed. Pessoa - Universitária, 1998.

> CAVIQUIOLO, Suelen Christine; ROCHA, Viviane da Costa; VASQUES; Rosana Aparecida; YANO, Laís Tinami Nozaki; FONTOURA, Antônio Martiniano. Design đ̇ Emoção: Desenvolvimento de Produtos com Foco na Experiência Emocional do Usuário. Curitiba: $7^{\circ}$ Congresso Brasileiro de Pesquisa At Desenvolvimento em Design, 2006.

$>$ DESCARTES, René. Discurso do método. São Paulo: Abril Cultura, 1973. Col. Os Pensadores, vol. XV.

> DUTRA, Luiz Henrique de Araújo. Oposições Filosóficas, a epistemologia e suas polêmicas. Florianópolis: Ed. UFSC, 2005.

> DONDIS, Donis. Carácter e conteúdo do alfabetismo visual. São Paulo: Ed. Martins Fontes, 1999.

> GIL, Antônio Carlos. Como elaborar projetos de pesquisa. 3Ć. Ed., São Paulo: Atlas, 1991.

> GOMEZ, Luiz Salomão Ribas. PEREIRA, Alice Theresinha Cybis. SCHLEMPER, Paula Felipe. Os $4 p$ 's do Design: Uma proposta metodológica não linear de projeto.

2010. Disponível em: http://pt.scribd.com/doc/36684758/4-P-s-do-Design. Acesso: 15/06/12

> JAPIASSÚ, Hilton; MARCONDES, Danilo. Dicionário Básico de Filosofia. 3ć ed.. Rio de Janeiro, 2001.

> LANA, Sebastiana Luiza Bragança. A complexidade dos métodos em design. Cadernos de Estudos Avançados em Design: Método-Barbacena, MG: EdUEMG, 2011 - p. 53-65.

> LISBOA, Maria da Graça Portela, BISOGNIN, Edir Lucia. Estética e Design. Disciplinarum Scientia. Série: Artes, Letras e Comunicação, Santa Maria, v. 4, n. 1, p. 77-86, 2003.

> LÖBACH, Bernd. Design industrial: bases para a configuração dos produtos industriais. Rio de Janeiro: Ed. Edgard Bhneher Ltda., 2001.

> MARCONDES, Danilo. Juízo, suspensão do juízo e filosofia cética. Revista SKÉPSIS, nć. 1, 2007.

> MARTINS, Rosane Fonseca de Freitas, MERINO, Eugenio Andrés Díaz. Gestão de Design como Estratégia Organizacional. 2ć. ed.. Londrina: EDUEL, 2011.

> MERINO, Giselle; GONTIJO, Leila Amaral; MERINO, Eugenio. 0 percurso do Design: no ensino e na prática. Cadernos de Estudos Avançados em Design: Método Barbacena: EdUEMG, 2011.p.67-85.

> MORA, José Ferrater. Dicionário de Filosofia. Lisboa: Dom Quixote, 1978. 
> MORAES, Anamaria de; MONT'ALVÃO, Claúdia. Ergonomia: Conceitos e Aplicações

- Rio de Janeiro: 2AB, 2009.

> MORAES, Dijon De; DIAS, Regina; BOM CONSELHO, Rosemary. Cadernos de Estudos Avançados em Design: Método - Barbacena, MG: EdUEMG, 2011.

> MORAES, Dijon De. Metaprojeto: o design do design - São Paulo: Blucher, 2010.

$>$ MORENTE, Manuel Garcia. Fundamentos de Filosofia - Lições Preliminares. Ed. Mestre Jou, São Paulo, 1976.

> MOURA, Mônica. Design, Arte e Tecnologia. São Paulo: Edições Rosari, 2005.

> MOZOTA, Brigitte Borja de; KLÖPSCH, Cássia; COSTA, Filipe Campelo Xavier da. Gestão de Design: usando o design para construir valor de marca e inovação corporativa. Porto Alegre: Bookman, 2011.

> NIEMEYER, Lucy. Design no Brasil: Origens e instalação. Editora. Rio de Janeiro: $2 A B, 2007$.

> OLHATS, Magali; FLORIANO, Juliana; SOUZA, Richard Perassi Luiz de; GOMEZ, Luiz Salomão Ribas. PRAGMATISMO E DESIGN. Pesquisa em Foco v. 19, p. 13-26, 2011.

> VERDAN, André. 0 Ceticismo Filosófico. Florianópolis: Ed. UFSC. Trad.: CONTE, Jamir. 1998. > POMBO, Fátima; TSCHIMMEL, Katja. 0 sapiens e o demens no pensamento do design: a percepção como centro. Salvador, Revista Design em Foco: Universidade do Estado da Bahia, 2002.

Camila de Cássia das Dores Ogava, possui graduação em Desenho Industrial pela Faculdade de Ciencias e Tecnologia de Birigui (2009) e Especialista em Gestão de Design pela Universidade Federal de Santa Catarina (2011).Atualmente é aluna em nível de mestrado do Programa de Pós-graduação em Design e Expressão Gráfica na Universidade Federal de Santa Catarina (2012), atuando na linha de pesquisa de Cestão de Design, voltada para a aproximação do conceito para micro e pequenas empresas. Além disso, é Bolsista CNPQ pelo projeto Agente Local de Inovação no estado de Santa Catarina.

kmilakssia@hotmail.com

Erik Silva dos Santos, graduado em Design pela Universidade Federal do Amazonas e atualmente cursando o Mestrado em Design e Expressão Gráfica na Universidade Federal de Santa Catarina. Tem experiência em Design, atuando principalmente em Ergonomia, Ergodesign e Identidade Visual.

dossantos.erik@gmail.com

Alberto Ribeiro Palmieri, possui graduação em Desenho Industrial - Projeto de Produto pela Faculdade de Ciências e Tecnologia de Birigui (2009), e pós-graduação em nível de especialização em Gestão de Design pela Universidade Federal de Santa Catarina (2011). Atualmente é aluno em nível de mestrado 
no programa de Pós-graduação em Design e Expressão Gráfica na Universidade Federal de Santa Catarina, atuando na linha de pesquisa de Gestão de Design voltada para o desenvolvimento sustentável.

\section{albertopalmieri@live.com}

Richard Perassi Luiz de Sousa, doutor em Comunicação e Semiótica pela Pontifícia Universidade Católica de São Paulo (2001), Mestre em Educação pela Universidade Federal de Mato Grosso do Sul (1995), Bacharel em Desenho de Propaganda e Licenciado em Artes Plásticas pelo curso de Educação Artística da Universidade Federal de Juiz de Fora (1986). Atualmente, atua como professor associado da Universidade Federal de Santa Catarina, nos cursos de graduação e pós-graduação em Design (Pós-Design/UFSC) e no programa de Pós-Graduação em Engenharia e Cestão do Conhecimento (EGR/UFSC). Anteriormente, foi professor da Universidade Federal de Mato Grosso do Sul. Tem experiência nas áreas de Artes Visuais, Design, Comunicação, Semiótica e Educação, desenvolvendo os seguintes temas: Semiótica Visual, Arte, Design e Mídia, Identidade, Cultura e Comunicação das Marcas nas Organizações. É lider do grupo de pesquisa SIGMO/ UFSC - Significação da marca, informação e comunicação organizacional.

\section{albertopalmieri@live.com}

Eugenio Andrés Díaz Merino, possui graduação em Desenho Industrial pela Universidade Federal do Rio de Janeiro (1993), mestrado em Engenharia de Produção pela Universidade Federal de Santa Catarina (1996) e doutorado em Engenharia de Produção pela Universidade Federal de Santa Catarina (2000). Atualmente é professor associado II da Universidade Federal de Santa Catarina e coordena o Nucleo de Cestão de Design. Tem experiência na área de Design, com ênfase em Gestão de Design e na área de engenharia, especificamente com ergonomia, produto e processo. Participa dos programas de pós-graduaçao em Design e Engenharia de Produção ambos da UFSC. Faz parte do grupo de avaliadores do INEP/MEC e do Conselho Estadual de Educaçao de Santa Catarina na avaliação de cursos. É lider do grupo de pesquisa em gestao de design e pesquisador CNPq.

merino@cce.ufsc.br

Luiz Fernando Gonçalves de Figueiredo, possui graduação em Engenharia Sanitária pela Universidade Federal de Mato Grosso (1998), mestrado em Engenharia Civil pela Universidade Federal de Santa Catarina (1995) e doutorado em Engenharia de Produção pela Universidade Federal de Santa Catarina (2000). Atualmente é professor efetivo da Universidade Federal de Santa Catarina. Tem experiência na área de Ciência da Informação, com ênfase em Teoria Ceral da Informação, atuando principalmente nos seguintes temas: educação, gestão ambiental, ensino aprendizagem, sistema de informação e educação a distância, design e inovação social.

Iff@cce.ufsc.br 